\title{
The Outcomes of Acute Coronary Syndrome in Patients Suffering From Schizophrenia: A Systematic Review
}

Hanan Hannoodee ${ }^{1}$, Mahmoud Al Khalili ${ }^{1}$, Nyein Wint Yee Theik ${ }^{1}$, Oluwatimilehin E. Raji ${ }^{1}$, Priya Shenwai ${ }^{1}$, Rutul Shah ${ }^{2}$, Sahithi Reddy Kalluri ${ }^{1}$, Tinaz H. Bhutta ${ }^{1}$, Safeera Khan ${ }^{1}$

1. Internal Medicine, California Institute of Behavioral Neurosciences \& Psychology, Fairfield, USA 2. Internal Medicine, M.P. Shah Government Medical College, Jamnagar, IND

Corresponding author: Hanan Hannoodee, hhannoodee@gmail.com

\begin{abstract}
Acute coronary syndrome (ACS) is a principal cause of mortality and morbidity worldwide. Recent studies have suggested poorer outcomes in ACS patients who have a concurrent diagnosis of schizophrenia as compared with those without. However, the degree of interplay between schizophrenia and ACS remains poorly understood. For this reason, we conducted a systematic review on ACS outcomes in patients with schizophrenia by following the Preferred Reporting Items for Systematic Reviews and Meta-Analyses (PRISMA) guidelines. We collected relevant data from PubMed, Cochrane Library, PubMed central, Jisc Library Hub Discover, and the National Library of Medicine (NLM) and performed a thorough quality appraisal. Fourteen shortlisted, relevant studies were meticulously reviewed. Mortality and major adverse cardiac events (MACE), bleeding, and stroke were more prevalent in patients with a schizophrenia diagnosis compared to those without. Additionally, schizophrenia patients received suboptimal care and follow-up when compared to patients without a psychiatric diagnosis. Clinicians need to be aware that patients with schizophrenia have worse outcomes following ACS which may relate to biological, health care, or patientrelated factors.
\end{abstract}

Categories: Cardiology, Internal Medicine, Psychiatry

Keywords: acute coronary syndrome, myocardial infarction, schizophrenia, outcomes, acs, review article

\section{Introduction And Background}

Acute coronary syndrome (ACS) occurs as a result of sudden rupture of unstable atherosclerotic plaques with subsequent thrombus formation in the coronary arteries and loss of blood flow to the heart muscle [1]. It carries a significant burden of mortality and morbidity (heart failure, re-infarcts, arrhythmia), which may be reduced by the timely use of revascularization procedures and evidenced-based cardioprotective therapies [2-5]. Interestingly, mortality risk in patients with ACS has been suggested to be higher in patients with a previous diagnosis of schizophrenia [6].

Review began 07/19/2021 Review ended 07/28/2021 Published 08/08/2021

\section{(๑) Copyright 2021}

Hannoodee et al. This is an open access article distributed under the terms of the Creative Commons Attribution License CC-BY 4.0., which permits unrestricted use, distribution, and reproduction in any medium, provided the original author and source are credited.
Schizophrenia is a severe mental illness that causes considerable disability and higher rates of mortality with an estimated 15-25 years decrease in life expectancy in this group [7-8]. Odds of coronary heart disease were found to be higher in schizophrenia patients compared to the general population (odds ratio $(\mathrm{OR})=1.51$; 95\% CI: 1.47-1.55) [9]. Patients who have a diagnosis of schizophrenia are considered to be more vulnerable to cardiovascular diseases (CVD) than mentally healthy patients due to the high prevalence of CVD risk factors, such as obesity, metabolic disorder, diabetes, and smoking, in those patients [10-11]. Moreover, it has been shown that there is inequality in the management of ACS between patients with schizophrenia and mentally healthy patients with lower rates of revascularization and cardioprotective therapy prescriptions [12-16]. As a consequence, a number of recent studies have explored whether ACS outcomes are worse in patients with schizophrenia using various study designs [17].

There is variability and inconsistency in the results of the reviewed studies that are exploring the mortality and morbidity risk in schizophrenic patients who are diagnosed with ACS. The relationship is not fully explored yet, and a significant knowledge gap is still present when managing schizophrenia patients with ACS. Therefore, we are conducting this systematic review to evaluate the major outcomes of ACS in patients with a pre-existing schizophrenia diagnosis as compared to those without.

\section{Review}

\section{Methods}

We conducted a systematic review following Preferred Reporting Items for Systematic Reviews and MetaAnalyses (PRISMA) guidelines [18].

Data Collection and Search Strategy 
An electronic search of published studies was conducted to identify relevant articles on the following databases: PubMed, Cochrane Library, PubMed Central, and Medline, with some other relevant articles extracted from Jisc Library Hub Discover and National Library of Medicine (NLM).

The PubMed search strategy was based on an algorithm made with the use of MeSH terms (Medical Subject Headings) using the following keywords:

Schizophrenia OR ( "Schizophrenia/complications"[Majr] OR "Schizophrenia/epidemiology"[Majr] OR "Schizophrenia/mortality"[Majr] OR "Schizophrenia/physiopathology"[Majr]

OR "Schizophrenia/prevention and control"[Majr] OR "Schizophrenia/statistics and numerical data"[Majr] ) AND Acute coronary syndrome OR ACS OR( "Acute Coronary Syndrome/epidemiology"[Majr] OR "Acute Coronary Syndrome/etiology"[Majr] OR "Acute Coronary Syndrome/history"[Majr] OR "Acute Coronary Syndrome/mortality"[Majr] OR "Acute Coronary Syndrome/physiopathology"[Majr] OR "Acute Coronary Syndrome/prevention and control"[Majr] OR "Acute Coronary Syndrome/statistics and numerical data"[Majr] ) OR myocardial infarction OR MI OR (( "Myocardial Infarction/epidemiology"[Majr] OR "Myocardial Infarction/etiology"[Majr] OR "Myocardial Infarction/history"[Majr] OR "Myocardial Infarction/mortality" [Majr] OR "Myocardial Infarction/physiopathology"[Majr] OR "Myocardial Infarction/prevention and control" [Majr] OR "Myocardial Infarction/statistics and numerical data"[Majr] )).

Study Selection and Eligibility Criteria

All articles were transferred to a worksheet (Excel, Microsoft Inc, Redmond, WA). Duplicate articles were excluded. Each article was screened by title and abstract and was either included or excluded for relevance. All articles included were further evaluated by reviewing the full article text to exclude any irrelevant articles.

The inclusion criteria include all study types and designs from inception to the present day that are related to the topic of ACS in patients with schizophrenia. All population groups were included in this study. Only full-text articles were used, all of which were published in peer-reviewed journals. Any gray literature or unpublished articles were excluded. Non-English articles were also excluded.

\section{Risk of Bias Assessment}

The quality of included studies was assessed by the following tools:

a) Newcastle-Ottawa checklist - observational studies; b) AMSTAR checklist for systematic review and metaanalysis; c) Scale for the Assessment of Narrative Review Articles (SANRA) checklist - traditional review articles.

\section{Results}

Study Identification and Selection Results

The initial search yielded 368 published articles. Duplicates $(n=62)$ and non-English articles $(n=15)$ were removed, leaving 291 articles to be screened by title and abstract for relevance. Of these, 193 articles were excluded for not being relevant. The full texts of the remaining 98 articles were thoroughly read, and 73 of them were excluded after inclusion/exclusion criteria were applied. Lastly, after a meticulous quality assessment, 11 articles were further excluded, and finally, 14 articles were included in the review. Figure 1 depicts the search process in the form of a PRISMA flow diagram. 


\section{Cureus}

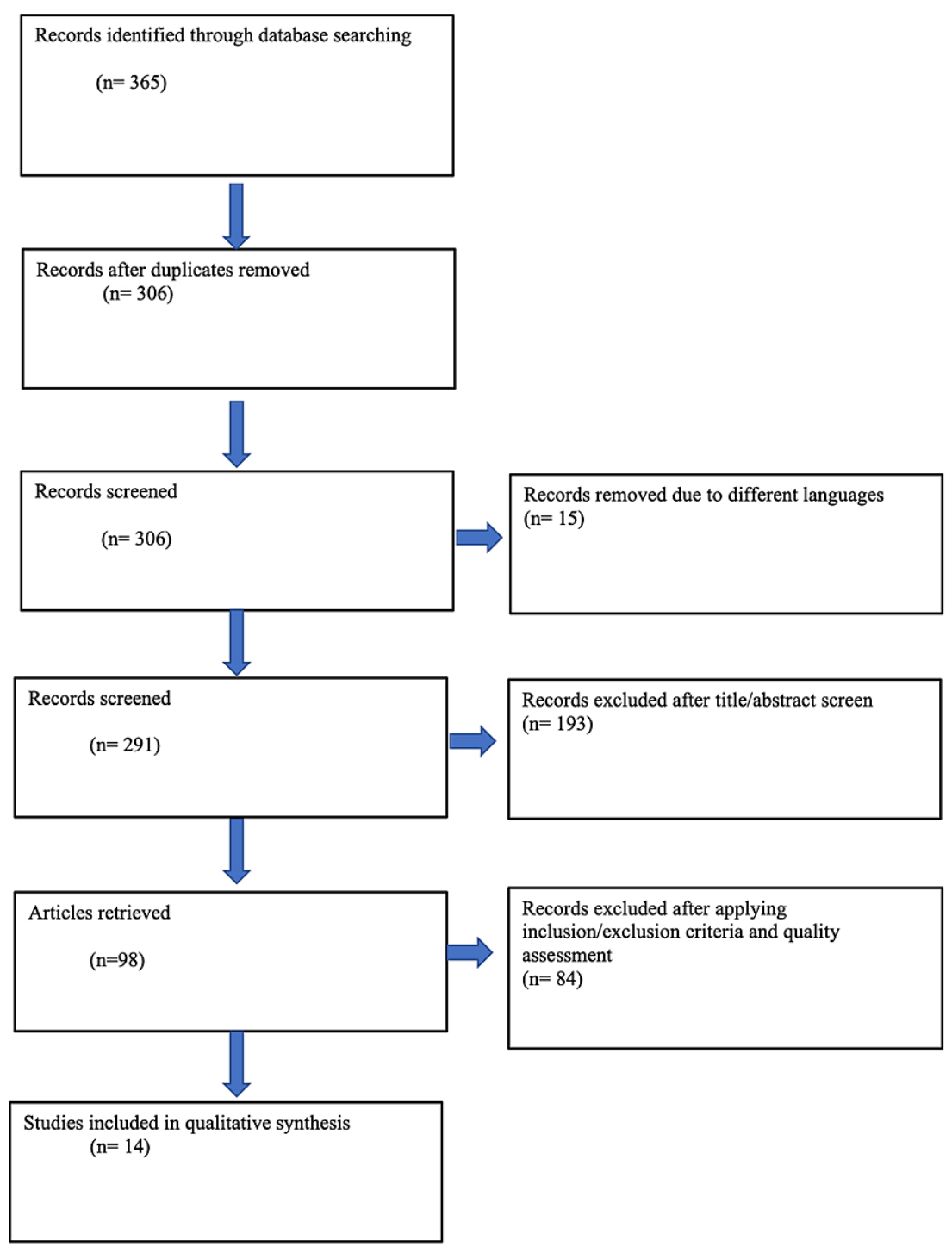

FIGURE 1: PRISMA flow diagram outlining the systematic review process

PRISMA: Preferred Reporting Items for Systematic Reviews and Meta-Analyses

Study Characteristics

In total, 14 articles were included in this review. The condition investigated was the outcomes of acute coronary syndrome in schizophrenia patients. Information about mortality rates from ACS in schizophrenia patients was found in these articles, of which 13 were observational or cohort studies and one was a metaanalysis. The study sample sizes ranged from 188 patients to 23,582 patients with a study duration of one year to 36 years. Four observational studies demonstrated additional information about major comorbidities, including major adverse cardiac events (MACE): re-infarction, stroke, and death and bleeding.

\section{Main Findings}

Fourteen studies that looked into the mortality outcome in schizophrenia patients with a diagnosis of ACS were summarized in Table 1 . The studies employed various statistical methods that mostly showed an increased risk of mortality with an odds ratio (OR)/hazard ratio (HR) ranging from 1.1 to 15.47. Two studies showed no difference in 30 days mortality [19-20]. 


\section{Cureus}

\begin{tabular}{|c|c|c|c|c|c|}
\hline & $\begin{array}{l}\text { Author, year, } \\
\text { reference }\end{array}$ & Country & Study design & Influence on mortality & Outcome \\
\hline 1 & $\begin{array}{l}\text { Attar R. 2020, } \\
\text { [16] }\end{array}$ & Sweden & $\begin{array}{l}\text { Observational } \\
\text { follow-up }\end{array}$ & Increased & aHR 2.38 (95\% Cl 1.84-3.09); $p<0.005$ \\
\hline 2 & $\begin{array}{l}\text { Shao M. 2020, } \\
\text { [6] }\end{array}$ & - & Meta-analysis & Increased & RR 1.66 (95\% Cl 1.33-2.09); $p<0.001$ \\
\hline 3 & $\begin{array}{l}\text { Hauck T. S. } \\
2020,[21]\end{array}$ & Canada & $\begin{array}{l}\text { Cohort } \\
\text { population- } \\
\text { based }\end{array}$ & Increased & HR 1.55 (95\% Cl 1.37-1.77) \\
\hline 4 & $\begin{array}{l}\text { Chang W. C. } \\
\text { 2020, [22] }\end{array}$ & $\begin{array}{l}\text { Hong } \\
\text { Kong }\end{array}$ & $\begin{array}{l}\text { Cohort } \\
\text { population- } \\
\text { based }\end{array}$ & Increased & $\begin{array}{l}\text { 30-day mortality OR } 1.99 \text { (95\% Cl 1.65- 2.39). } \\
\text { 1-year mortality OR } 2.13(95 \% \mathrm{Cl} 1.79-2.54)\end{array}$ \\
\hline 5 & $\begin{array}{l}\text { Attar R. 2019, } \\
\text { [23] }\end{array}$ & Denmark & $\begin{array}{l}\text { Cohort } \\
\text { population- } \\
\text { based }\end{array}$ & Increased & HR 2.54 (95\% Cl 2.22-2.90) \\
\hline 6 & $\begin{array}{l}\text { Mohamed M. O. } \\
\text { 2019, [24] }\end{array}$ & $\begin{array}{l}\text { United } \\
\text { States }\end{array}$ & $\begin{array}{l}\text { Retrospective } \\
\text { observational }\end{array}$ & Increased & OR 1.10 (95\% Cl 1.04-1.16) \\
\hline 7 & $\begin{array}{l}\text { Westman J. } \\
\text { 2018, [25] }\end{array}$ & Sweden & Cohort study & Increased & MRR 2.62 (95\% Cl 2.49-2.75) \\
\hline 8 & $\begin{array}{l}\text { Kugathasan, } \\
\text { Pirathiv; 2018, } \\
\text { [19] }\end{array}$ & Denmark & Cohort study & $\begin{array}{l}\text { Increased long term mortality No } \\
\text { difference in } 30 \text {-day mortality }\end{array}$ & aHR 15.47 (95\% Cl 12.62-18.96) \\
\hline 9 & $\begin{array}{l}\text { Protty M. B. } \\
2017,[26]\end{array}$ & $\begin{array}{l}\text { United } \\
\text { Kingdom }\end{array}$ & $\begin{array}{l}\text { Retrospective } \\
\text { cohort }\end{array}$ & Increased & HR 1.38 (95\% Cl 1.24-1.54); $p<0.05$ \\
\hline 10 & $\begin{array}{l}\text { Schulman- } \\
\text { Marcus J. 2016, } \\
\text { [27] }\end{array}$ & $\begin{array}{l}\text { United } \\
\text { States }\end{array}$ & $\begin{array}{l}\text { Observational } \\
\text { follow-up }\end{array}$ & Increased & OR 1.31 (95\% Cl 1.24-1.40); $p<0.001$ \\
\hline 11 & $\begin{array}{l}\text { Bodén R. 2015, } \\
\text { [28] }\end{array}$ & Sweden & Cohort study & Increased & $\begin{array}{l}\text { 30-day mortality OR } 2.58(95 \% \mathrm{Cl} 1.88-3.54) .1 \text { - } \\
\text { year mortality OR } 2.55(95 \% \mathrm{Cl} 1.98-3.29)\end{array}$ \\
\hline 12 & $\begin{array}{l}\text { Wu S. I. 2013, } \\
\text { [29] }\end{array}$ & Taiwan & Case-control & Increased & OR 2.68 (95\% Cl 1.73-4.15) \\
\hline 13 & $\begin{array}{l}\text { Kurdyak P. } \\
\text { 2012, [30] }\end{array}$ & Canada & $\begin{array}{l}\text { Retrospective } \\
\text { cohort }\end{array}$ & Increased & $\begin{array}{l}\text { 30-day mortality aOR } 1.56(95 \% \text { Cl 1.08-2.23); } \\
p=0.02\end{array}$ \\
\hline 14 & $\begin{array}{l}\text { Druss B. G. } \\
2000,[20]\end{array}$ & $\begin{array}{l}\text { United } \\
\text { States }\end{array}$ & $\begin{array}{l}\text { Retrospective } \\
\text { cohort }\end{array}$ & No difference in 30-day mortality & 30-day mortality RR 0.95; p.18 \\
\hline
\end{tabular}

\section{TABLE 1: Mortality outcome in schizophrenia patients with ACS}

aHR = adjusted hazard ratio; $\mathrm{RR}$ = relative risk; $\mathrm{HR}$ = hazard ratio; $\mathrm{OR}=$ odd Ratio; $\mathrm{Cl}$ = confidence interval; $\mathrm{MRR}=$ mortality rate ratio; aOR = adjusted odd ratio.

Upon further review, we were able to identify nine studies that looked more in-depth at the mortality rates in schizophrenic patients after ACS (Table 2). They were adjusted for different variables in an attempt to remove any confounding bias. Some of these studies noted large increases in the HR of death even after adjusting for factors like age, sex, smoking, comorbidities, previous coronary angiography (CAG) and previous percutaneous coronary intervention (PCI), discharge medication, and treatment with CAG and PCI. However, a study by Druss BG et al. noted only modest changes after adjusting for percutaneous transluminal coronary angioplasty (PTCA) and coronary artery bypass graft (CABG) [20]. Adjusting for time to revascularization as expected resulted in improvement in mortality HR since many schizophrenic patients tend to have delays in receiving revascularization procedures [21]. 


\section{Cureus}

\begin{tabular}{|c|c|c|c|c|}
\hline No & $\begin{array}{l}\text { Author, } \\
\text { reference }\end{array}$ & Unadjusted ratio & Adjusted ratio & Criteria adjusted \\
\hline 1 & $\begin{array}{l}\text { Attar R. et } \\
\text { al [16] }\end{array}$ & $\begin{array}{l}\text { 5-year mortality HR } \\
1.44(95 \% \mathrm{Cl} 1.31-1.59)\end{array}$ & $\begin{array}{l}\text { HR } 2.38(95 \% \text { Cl 1.84- } \\
3.09)\end{array}$ & $\begin{array}{l}\text { Age, sex, smoking, comorbidities, previous } \mathrm{CAG} \text { and previous } \\
\mathrm{PCl} \text {, discharge medication, and treatment with } \mathrm{CAG} \text { and } \mathrm{PCI} \text {. }\end{array}$ \\
\hline 2 & $\begin{array}{l}\text { Hauck T. S. } \\
\text { et al [21] }\end{array}$ & Unavailable & $\begin{array}{l}\text { HR } 1.38(95 \% \text { Cl } 1.20- \\
1.58)\end{array}$ & Time-varying revascularization \\
\hline 3 & $\begin{array}{l}\text { Chang W. } \\
\text { [22] }\end{array}$ & $\begin{array}{l}30 \text {-day mortality OR } \\
1.67 \text { (95\% Cl 1.40-1.98) } \\
1 \text {-year mortality OR } \\
1.67(95 \% \text { Cl } 1.44-1.95)\end{array}$ & $\begin{array}{l}\text { OR } 1.99 \text { (95\% Cl } 1.65- \\
2.39) 1 \text {-year mortality } \\
\text { OR } 2.13(95 \% \text { Cl } 1.79- \\
2.54)\end{array}$ & $\begin{array}{l}\text { Age, sex, calendar-year period of index admission, and } \\
\text { medical comorbidities. }\end{array}$ \\
\hline 4 & $\begin{array}{l}\text { Kugathasan } \\
\text { P. [19] }\end{array}$ & $\begin{array}{l}\text { HR } 18.61(95 \% \mathrm{Cl} \\
16.31-21.24)\end{array}$ & $\begin{array}{l}\text { HR } 15.47(95 \% \mathrm{Cl} \\
12.62-18.96)\end{array}$ & $\begin{array}{l}\text { Age at entry, gender, calendar year, diabetes, hypertension, } \\
\text { hyperlipidemia, and COPD. }\end{array}$ \\
\hline 5 & $\begin{array}{l}\text { Schulman- } \\
\text { Marcus J. } \\
\text { [27] }\end{array}$ & $\begin{array}{l}\text { In-hospital mortality } \\
\text { OR } 1.41(95 \% \text { Cl 1.35- } \\
1.47)\end{array}$ & $\begin{array}{l}\text { OR } 0.85(95 \% \mathrm{Cl} 0.70- \\
1.02)\end{array}$ & $\begin{array}{l}\text { Age, gender, race, payer, hospital characteristics, co- } \\
\text { morbidities, previous revascularization, and cardiogenic } \\
\text { shock. }\end{array}$ \\
\hline 6 & $\begin{array}{l}\text { Bodén R. } \\
\text { [28] }\end{array}$ & Unavailable & $\begin{array}{l}\text { 30-day mortality OR } \\
2.58(95 \% \mathrm{Cl} 1.88-3.54) \\
1 \text {-year mortality OR } \\
2.55(95 \% \mathrm{Cl} 1.98-3.29)\end{array}$ & $\begin{array}{l}\text { Age, gender, smoking, diabetes, previous hypertension, heart } \\
\text { failure, stroke, peripheral vascular disease, infarction type, } \\
\text { Killip classification, biomarker level, acute treatments, and } \\
\text { secondary preventative drugs. }\end{array}$ \\
\hline 7 & Wu S. I. [29] & Unavailable & $\begin{array}{l}\text { In-patient mortality OR } \\
2.68(95 \% \mathrm{Cl} 1.73-4.58)\end{array}$ & $\begin{array}{l}\text { Demographic characteristics (age at first AMI, level of income, } \\
\text { and level of urbanization), medical disorders, cardiac history, } \\
\text { hospital properties, inpatients complications, and any } \\
\text { catheterization or revascularization receipt }\end{array}$ \\
\hline 8 & $\begin{array}{l}\text { Kurdyak P. } \\
\text { [30] }\end{array}$ & $\begin{array}{l}\text { OR } 1.64(95 \% \text { Cl 1.15- } \\
2.32)\end{array}$ & $\begin{array}{l}\text { OR } 1.56(95 \% \text { Cl 1.08- } \\
2.23)\end{array}$ & $\begin{array}{l}\text { Age, sex income, hospitalization length of stay, comorbidities } \\
\text { (ambulatory diagnostic groups), rurality and cardiologist and } \\
\text { primary care visits in the year prior to incident AMI. }\end{array}$ \\
\hline 9 & $\begin{array}{l}\text { Druss B. G. } \\
\text { [20] }\end{array}$ & Unavailable & $\begin{array}{l}\text { 30-day mortality RR } \\
0.95 ; \text { P } 0.18\end{array}$ & $\begin{array}{l}\text { Demographic variables, cardiac risk factors, and history, } \\
\text { admission characteristics, left ventricular function availability } \\
\text { of technology, and transfer status plus PTCA and CABG. }\end{array}$ \\
\hline $\begin{array}{l}\mathrm{HR}= \\
\text { myoc } \\
\text { CABG }\end{array}$ & $\begin{array}{l}\text { ardial infarction; } \\
=\text { coronary arte }\end{array}$ & $\begin{array}{l}\beta=\text { odd ratio; } \mathrm{Cl}=\text { confidenc } \\
; \mathrm{COPD}=\text { chronic obstructiv } \\
\text { ery bypass graft }\end{array}$ & $\begin{array}{l}\text { interval; } \mathrm{CAG}=\text { coronary } \\
\text { pulmonary disease; } \mathrm{RR}=\end{array}$ & $\begin{array}{l}\text { Ingiography; } \mathrm{PCI}=\text { percutaneous coronary intervention; } \mathrm{AMI}=\text { acute } \\
\text { elative risk; PTCA = percutaneous transluminal coronary angioplasty; }\end{array}$ \\
\hline
\end{tabular}

\section{Discussion}

This review systematically analyzes the existing literature on how a diagnosis of schizophrenia affects rates of mortality and morbidity in patients with ACS and what factors make those patients more susceptible to poorer outcomes. Although the results of the studies were not always in agreement, this review found a clear pattern of higher mortality in patients with schizophrenia who suffer from ACS when compared with psychiatric healthy patients as will be discussed below. In addition, patients with schizophrenia represent a multi-morbid cohort with a higher cardiovascular risk and a more significant burden of comorbidities than those without schizophrenia. We therefore also discuss inequality in the care provided to patients with schizophrenia which may explain some of our findings.

Mortality Risk in Patients With Schizophrenia and ACS

Mortality rates in schizophrenia patients with ACS did not decrease over the last two decades in spite of the general trend of decreasing mortality rates from ACS in patients worldwide [6,31]. This is described by Westman J et al. through a national registry study (1987-2010) in Sweden which found that coronary heart disease and cerebrovascular disease were the two most frequent cardiovascular causes of death in patients with schizophrenia with ACS being responsible for more than half the deaths from coronary heart disease in those patients (mortality rate ratio (MRR) 2.62; 95\% CI 2.49-2.75) [25]. Indeed, in a large cohort study of ACS patients reported by Pirathiv et al., patients with schizophrenia had increased rates of mortality in the 36year study period (1980-2015) compared with ACS patients without schizophrenia (hazard ratios (HR) 15.47; 95\% CI 12.62-18.96) [19]. A more contemporary study from the UK by Protty MB et al. reported a similar 
conclusion but with a more modest increase in mortality over their study period 2004-2014 (HR 1.38; $95 \%$ CI: 1.24-1.54) [26]. Similar findings were reported by others as demonstrated in Table 1.

A diagnosis of schizophrenia has drastic consequences on the patients, not only on long-term post-ACS mortality but also on short-term and inpatient mortality. That was described by some authors who specifically investigated the 30-day mortality rate in schizophrenia patients with ACS. Kurdyak P et al. [30], Boden $\mathrm{R}$ et al. [28], and Hauck TS et al. [21] demonstrated a noteworthy rise in the 30-day mortality rate in those patients with an adjusted odds ratio (aOR) of (1.56; 95\% CI 1.08-2.23), (2.58; 95\% CI 1.88-3.54), and (1.55; 95\% CI 1.37-1.77), respectively. Furthermore, Chang WC described similar results of higher 30-day mortality (OR 1.99; 95\% CI 1.65-2.39) although they derived this cohort study group from patients who were diagnosed with psychotic disorders and not only schizophrenia [22]. Two studies looked more specifically at the mortality risk during the ACS event hospitalization. These studies were done by Schulman-Marcus J et al. and Wu SI et al., who noted higher inpatient mortality in patients with schizophrenia with OR 1.31 (95\% CI 1.24-1.40) and 2.68 (95\% CI 1.73-4.15), respectively [27,29]. Despite these reports, however, a number of studies demonstrated the conflicting findings of no difference in 30-day mortality from ACS in patients with schizophrenia as compared to those without [19]. These studies may have been limited however by smaller sample size ( $\mathrm{n}=188$ in a study by Druss et al., older population (>65), or historic when interventions were not as readily available as in later years [20].

There are several potential causes to the observed increased long-term and 30-day mortality rates in schizophrenia patients with ACS. An important cause could be due to the lack of adjustment in different criteria (age, sex, smoking, previous PCI, other comorbidities, and timing of revascularization) between patients with and without schizophrenia. As summarized in Table 2, a recent study in 2020 by Attar R et al. described their findings on 1008 schizophrenic patients who experienced MI during 2018-2020. A remarkable expansion in mortality rate was noted in those patients when adjusted for age and sex only (HR $2.99,95 \%$ CI 2.72-3.29). However, mortality-adjusted HR was reduced (aHR=2.38; 95\% CI 1.84-3.09) when further factors were adjusted (smoking, comorbidities, previous PCI and coronary angiography, discharge medication, and treatment with coronary angiography and PCI) [16]. In support of this view, 1,145 schizophrenia patients with acute myocardial infarction (AMI) were studied by Hauck TS et al., who outlined a high mortality rate in those patients (HR 1.55; 95\% CI, 1.37-1.77), which was reduced after adjustment for time-varying revascularization (aHR 1.38; 95\% CI 1.20-1.58) [21]. Similar findings were seen in a study by Kugathasan P et al., which demonstrated a crude mortality HR of 18.61 (95\%CI 16.31-21.24) in schizophrenia patients with ACS, which decreased to 15.47 (95\% CI 12.62-18.96) after being adjusted for age, gender, calendar year, diabetes, hypertension, hyperlipidemia, and chronic obstructive pulmonary disease (COPD) [19]. To summarize, the overall trend shows us that there are confounding factors that increase the mortality of ACS in schizophrenic patients, such as smoking, BMI, demographic factors (income, urbanization), which may vary between studies. Another crucial factor is the overall trend in delay or not pursuing revascularization, which may vary by the health system.

Another possible cause of that increased observed trend is merging schizophrenia with other psychotic disorders and grouping patients into a broadly defined category of severe mental illness without being specific to only schizophrenia. This might participate in the described higher mortality rate in the cohort group when compared to the control group (patients with no psychotic disorders). Elevated one-year mortality after ACS was reported to be high in patients with psychotic disorders (schizophrenia, schizoaffective disorder, persistent delusional disorder, acute and transient psychotic disorders, and unspecified non-organic psychosis) by Chang W et al. (unadjusted OR 2.13; 95\% CI 1.79-2.54). Even after being adjusted to age, sex, calendar-year period of index admission, and medical comorbidities, the mortality rate was persistently high (aOR 2.13; 95\% CI 1.79-2.54; $\mathrm{p}<0.001$ ) [22]. Furthermore, differences in study designs and statistical methods involved might give a reason for the noted variability.

Not only were mortality rates higher, but also patients with schizophrenia tend to die at younger ages if they have ACS. A 15 to 25 -year decrease in life expectancy in schizophrenic patients has been described in the literature $[7-8]$. This decrease can potentially be attributed to ACS complications. Westman J et al. looked specifically into this question and noted that death from ACS occurs at an earlier age in schizophrenia patients with a high early death $(<60)$ in schizophrenia patients with ACS (MRR 5.39; 95\% CI 4.84-6.00) [25]. This can possibly be attributed to patient factors and healthcare factors that will be discussed further in the next paragraphs.

\section{Morbidity of ACS in Patients With Schizophrenia}

On their own, a diagnosis of either schizophrenia or ACS comes with a significant burden of morbidity that worsens when both conditions are combined. This combination is frequently observed with a higher risk of adverse outcomes, such as cardiovascular morbidities, stroke, and bleeding, noted in schizophrenia patients, as will be described below.

In our systematic review, we studied the main outcome of ACS in patients with schizophrenia. Major adverse cardiac events (MACE) are prominent outcomes. Two different studies by Attar R et al. and a third study by Protty MB et al. reported a notable rise in MACE rates in those patients when compared to psychiatric 
healthy patients with HR of (2.05; 95\% CI 1.63-2.58), (1.62; 95\% CI 1.45-1.81), and (1.20; 95\% CI 1.09-1.31; $\mathrm{p}=0.05$ ), respectively $[16,23,26]$. One important component of MACE post-ACS is stroke, which was reported to be higher in patients with schizophrenia. Specifically, stroke rates after ACS were studied by Attar R et al. and Protty MB. et al., revealing a statistically significant increase in the incidence of stroke in patients with schizophrenia versus those without, with HR (1.72; 95\% CI 1.00-2.98; p<0.005), (1.51; 95\% CI 1.15-1.99, $\mathrm{p}=0.0033)$ and $(1.28 ; 95 \%$ CI 1.13-1.85; $\mathrm{p}<0.05)$, respectively $[16,23,26]$.

Another serious complication of ACS after hospital discharge is bleeding, which is found to be higher in prevalence in patients with severe mental illness and more specifically in patients with a previous diagnosis of schizophrenia [26]. This could be attributed to the use of some medications. Antipsychotics (typical and atypical) through an unknown mechanism have been correlated to a higher risk of intracranial hemorrhage particularly in senior patients [32-33]. Moreover, antidepressants such as selective serotonin reuptake inhibitors (SSRI) have also been reported to have a side effect of more bleeding [34]. Two statistically significant studies reported contrasting results regarding bleeding after ACS $[24,26]$. A study was done by Protty MB et al in the United Kingdom showed an elevated bleeding rate (HR 1.35; 95\% CI 1.15-1.58), whilst a reduced bleeding rate (OR $0.70,95 \%$ CI $0.65-0.75)$ was noted in a national analysis of all hospitalization with AMI in the United States by Mohamed MO et al. Dissimilarity in healthcare system between the two countries (the United States and the United Kingdom) may contribute to that observed difference in the results.

Reassuringly, there were no differences reported in the reinfarction rates after ACS in patients with versus without schizophrenia as demonstrated by Attar R et al. (HR 0.88; 95\% CI 0.73-1.07) and Protty MB et al. (HR 1.02 ; $95 \%$ CI 0.89-1.17) $[23,26]$.

Possible Reasons to the Increased Mortality and Morbidity in Patients With Schizophrenia Post-ACS

Patient factors: The prevalence of cardiovascular disease and its risk factors are reported to be higher in patients with schizophrenia compared to the general population. For instance, the prevalence of diabetes mellitus has been observed to be at least two times as high as in the general population [10]. Also, the prevalence of metabolic syndrome in schizophrenia patients is up to four-fold the prevalence in the general population [10]. This may be mechanistically explained by pharmacological influence inferred by the use of medications such as antidepressants and antipsychotics, which have been linked to an increased risk of metabolic syndrome. These drugs interfere with glucose metabolism and thus weight control via interaction with target 5-hydroxytryptamine neuroreceptors. Thus, place patients on those medications are at an increased risk of ACS and its complication including all-cause bleeding, death, and stroke [35-41]. Obesity, anemia, COPD, peripheral arterial disease (PAD), and cardiomyopathy were reported to be more prevalent among patients with schizophrenia when compared to the general population [23].

Socioeconomic factors, such as poverty and lower educational attainment, are more prevalent in patients with schizophrenia compared to those without [17]. When these factors are combined with behavioral risk factors seen in patients with schizophrenia, such as substance abuse, tobacco smoking, sedentary lifestyle, and obesity, they may culminate in increased susceptibility to developing cardiac risk factors (like diabetes and metabolic syndrome) and not pursuing positive health choices $[8,10]$. Figure 2 highlights those factors, which may all contribute to the poor outcomes experienced by patients suffering from schizophrenia. 


\section{Cureus}

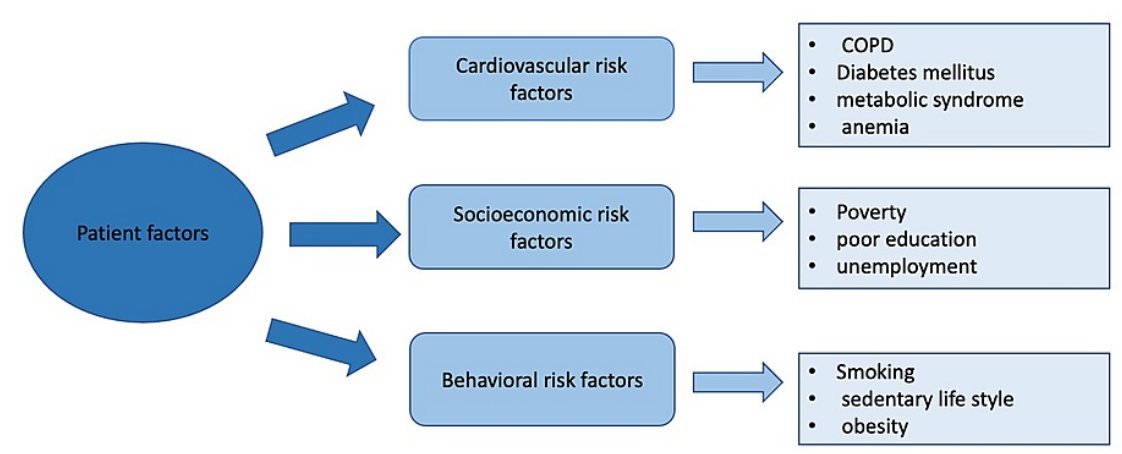

FIGURE 2: ACS risk factors in patients with schizophrenia

ACS: acute coronary syndrome

Healthcare factors: It is possible that patients suffering from schizophrenia receive suboptimal care at multiple levels in the healthcare system, which may lead to the persistently higher-than-expected mortality from ACS when compared to the general population $[23,26]$. Starting with primary prophylactic management, cardiovascular risk factors, documentation, and management are reported to be suboptimal in patients with schizophrenia [17]. Moreover, rates of revascularization post-ACS in patients with schizophrenia are almost half as much as those seen in the general population [17]. In addition, during the post-myocardial infarction (MI) care, there are further dissimilarities in providing care, with lower rates of cardiology specialist visits in the 30-days post-ACS in patients with schizophrenia when compared to those without (12.2\% vs $20.1 \%$, respectively) [30]. Other secondary prevention measures were also lower in schizophrenia patients, including the prescription of statins, beta-blockers, and anti-platelets [16].

This suboptimal healthcare may be due to subconscious bias and stereotyping by health care providers when taking care of patients with severe mental illnesses overall and with schizophrenia specifically by deprioritizing those patients during ACS events [16]. There seems to be a preset perception that this population is poorly compliant, difficult to obtain medical or surgical treatment consents, and overall challenging to treat [27]. All of these perceptions may discourage healthcare staff from providing proper high-level care. These biases should be recognized and effectively managed when dealing with this vulnerable population with more attention given to ensuring proper follow-up arrangements. New guidelines should be placed to assist providers in the management of this cohort in the urgent setting of unstable medical and psychological issues. Figure 3 focuses its attention on the healthcare factors, which may lead to poor outcomes in patients with schizophrenia who suffer from ACS. 


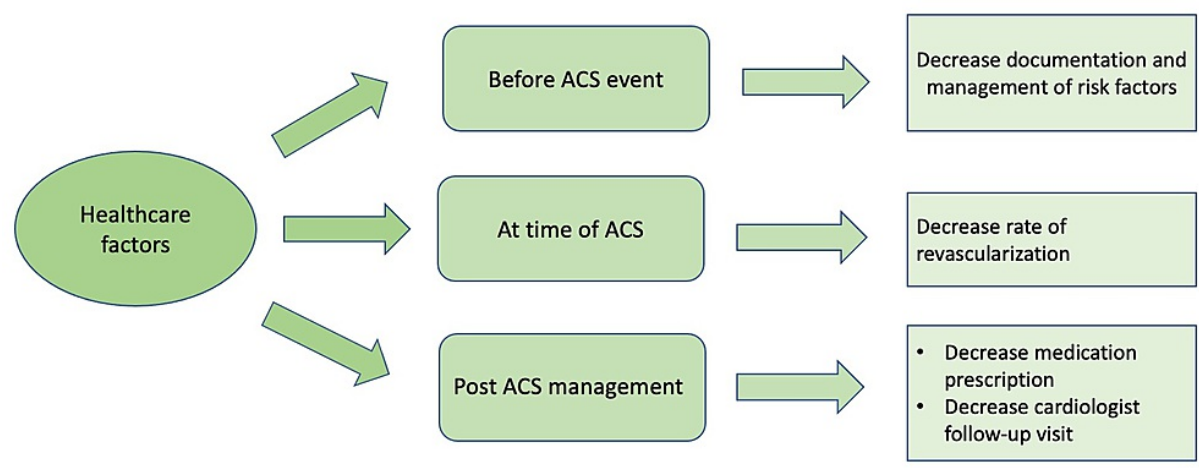

\section{FIGURE 3: Health care factors that influence prognosis on schizophrenic patients with ACS diagnosis}

ACS: acute coronary syndrome

\section{Limitations}

All the included studies were retrospective studies, which may be limited by missing data, poor coding, or poor follow-up of participants. For this reason, a prospective study is needed to investigate mortality and morbidity following ACS in schizophrenia patients and to see how patient education about risk factors and lifestyle changes can affect those outcomes. Another limitation to this review is the exclusion of studies in languages other than English, which might have created an unintentional bias in our systematic review.

\section{Conclusions}

In this systematic review, we explored the impact of schizophrenia on mortality and morbidity outcomes following an initial event of ACS. Death rates following ACS were reported to be higher in patients who were previously diagnosed with schizophrenia when compared to mentally healthy patients. Furthermore, schizophrenia patients suffering from ACS were reported to be at a greater risk of major complications after hospital discharge, including MACE, bleeding, and stroke compared to the general population. The causes for these findings are likely multifactorial, relating to patient factors (cardiovascular risk, behavioral, and socioeconomic factors), as well as healthcare factors (possible treatment bias, prejudice, and suboptimal care), which may contribute to the higher burden of mortality and morbidity in patients with schizophrenia. Patient education about risk factors, likely complications, and behavior modification may be employed alongside improving physician awareness of treatment inequality, management of mental health comorbidities, and encouraging social group and family support for schizophrenia patients. The effectiveness of any such measures needs to be assessed and addressed by future studies on this patient group.

\section{Additional Information}

\section{Disclosures}

Conflicts of interest: In compliance with the ICMJE uniform disclosure form, all authors declare the following: Payment/services info: All authors have declared that no financial support was received from any organization for the submitted work. Financial relationships: All authors have declared that they have no financial relationships at present or within the previous three years with any organizations that might have an interest in the submitted work. Other relationships: All authors have declared that there are no other relationships or activities that could appear to have influenced the submitted work.

\section{Acknowledgements}

We would like to heartily acknowledge Dr. Majd Protty (Cardiology, Cardiff University, Cardiff, United Kingdom) and Dr. Rami Jirjis (Urology, Detroit Medical Center (DMC), Michigan, United States) for constant motivation and support throughout the article writing and for recognizing "Microsoft Word" and "Mendeley Desktop" for providing a platform for this article.

\section{References}


1. Eisen A, Giugliano RP, Braunwald E: Updates on acute coronary syndrome. A review . JAMA Cardiol. 2016, 1:718-30. 10.1001/jamacardio.2016.2049

2. Rodriguez F, Mahaffey KW: Management of patients with NSTE-ACS: a comparison of the recent AHA/ACC and ESC guidelines. J Am Coll Cardiol. 2016, 68:313-21. 10.1016/j.jacc.2016.03.599

3. Levine GN, Bates ER, Bittl JA, et al.: 2016 ACC/AHA Guideline focused update on duration of dual antiplatelet therapy in patients with coronary artery disease: a report of the American College of Cardiology/American Heart Association Task Force on Clinical Practice Guidelines: an update of the 2011 ACCF/AHA/SCAI Guideline for Percutaneous Coronary Intervention, 2011 ACCF/AHA Guideline for Coronary Artery Bypass Graft Surgery, 2012 ACC/AHA/ACP/AATS/PCNA/SCAI/STS Guideline for the diagnosis and management of patients with stable ischemic heart disease, 2013 ACCF/AHA Guideline for the management of ST-elevation myocardial infarction, 2014 AHA/ACC Guideline for the management of patients with non-ST-elevation acute coronary syndromes, and 2014 ACC/AHA Guideline on perioperative cardiovascular evaluation and management of patients undergoing noncardiac surgery. Circulation. 2016, 134:e123-55. 10.1161/CIR.0000000000000404

4. Benjamin EJ, Muntner P, Alonso A, et al.: Heart disease and stroke statistics-2019 update: a report from the American Heart Association. Circulation. 2019, 139:e56-e528. 10.1161/CIR.0000000000000659

5. Roth GA, Forouzanfar MH, Moran AE, et al.: Demographic and epidemiologic drivers of global cardiovascular mortality. N Engl J Med. 2015, 372:1333-41. 10.1056/NEJMoa1406656

6. Shao M, Tian H, Wang L, Jiang D, Ji F, Zhuo C: Mortality risk following acute coronary syndrome among patients with schizophrenia: a meta-analysis. Prog Neuropsychopharmacol Biol Psychiatry. 2020, 96:109737. 10.1016/j.pnpbp.2019.109737

7. Laursen TM, Wahlbeck K, Hällgren J, et al.: Life expectancy and death by diseases of the circulatory system in patients with bipolar disorder or schizophrenia in the Nordic countries. PLoS One. 2013, 8:e67133. 10.1371/journal.pone.0067133

8. Azad MC, Shoesmith WD, Al Mamun M, Abdullah AF, Naing DK, Phanindranath M, Turin TC: Cardiovascular diseases among patients with schizophrenia. Asian J Psychiatr. 2016, 19:28-36. 10.1016/j.ajp.2015.11.012

9. Correll CU, Solmi M, Veronese N, et al.: Prevalence, incidence and mortality from cardiovascular disease in patients with pooled and specific severe mental illness: a large-scale meta-analysis of 3,211,768 patients and 113,383,368 controls. World Psychiatry. 2017, 16:163-80. 10.1002/wps.20420

10. McEvoy JP, Meyer JM, Goff DC, et al.: Prevalence of the metabolic syndrome in patients with schizophrenia: baseline results from the Clinical Antipsychotic Trials of Intervention Effectiveness (CATIE) schizophrenia trial and comparison with national estimates from NHANES III. Schizophr Res. 2005, 80:19-32. 10.1016/j.schres.2005.07.014

11. de Leon J, Diaz FJ: A meta-analysis of worldwide studies demonstrates an association between schizophrenia and tobacco smoking behaviors. Schizophr Res. 2005, 76:135-57. 10.1016/j.schres.2005.02.010

12. Foguet-Boreu Q, Fernandez San Martin MI, Flores Mateo G, et al.: Cardiovascular risk assessment in patients with a severe mental illness: a systematic review and meta-analysis. BMC Psychiatry. 2016, 16:141. 10.1186/s12888-016-0833-6

13. Lahti M, Tiihonen J, Wildgust H, et al.: Cardiovascular morbidity, mortality and pharmacotherapy in patients with schizophrenia. Psychol Med. 2012, 42:2275-85. 10.1017/S0033291712000396

14. Mitchell AJ, Lawrence D: Revascularisation and mortality rates following acute coronary syndromes in people with severe mental illness: comparative meta-analysis. Br J Psychiatry. 2011, 198:434-41. 10.1192/bjp.bp.109.076950

15. Kritharides L, Chow V, Lambert TJ: Cardiovascular disease in patients with schizophrenia . Med J Aust. 2017, 207:179. 10.5694/mja17.00258

16. Attar R, Wester A, Koul S, et al.: Higher risk of major adverse cardiac events after acute myocardial infarction in patients with schizophrenia. Open Heart. 2020, 7 :e001286. 10.1136/openhrt-2020-001286

17. Protty MB: Coronary artery disease and schizophrenia: the interplay of heart and mind . Eur Heart J Qual Care Clin Outcomes. 2019, 5:90-1. 10.1093/ehjqcco/qcz005

18. Moher D, Liberati A, Tetzlaff J, Altman DG: Preferred reporting items for systematic reviews and metaanalyses: the PRISMA statement. PLoS Med. 2009, 6:e1000097. 10.1371/journal.pmed.1000097

19. Kugathasan P, Laursen TM, Grøntved S, Jensen SE, Aagaard J, Nielsen RE: Increased long-term mortality after myocardial infarction in patients with schizophrenia. Schizophr Res. 2018, 199:103-8. 10.1016/j.schres.2018.03.015

20. Druss BG, Bradford DW, Rosenheck RA, Radford MJ, Krumholz HM: Mental disorders and use of cardiovascular procedures after myocardial infarction. JAMA. 2000, 283:506-11. 10.1001/jama.283.4.506

21. Hauck TS, Liu N, Wijeysundera HC, Kurdyak P: Mortality and revascularization among myocardial infarction patients with schizophrenia: a population-based cohort study. Can J Psychiatry. 2020, 65:454-62. 10.1177/0706743720904845

22. Chang WC, Chan JK, Wong CS, Hai JS, Or PC, Chen EY: Mortality, revascularization, and cardioprotective pharmacotherapy after acute coronary syndrome in patients with psychotic disorders: a population-based cohort study. Schizophr Bull. 2020, 46:774-84. 10.1093/schbul/sbaa013

23. Attar R, Valentin JB, Freeman P, Andell P, Aagaard J, Jensen SE: The effect of schizophrenia on major adverse cardiac events, length of hospital stay, and prevalence of somatic comorbidities following acute coronary syndrome. Eur Heart J Qual Care Clin Outcomes. 2019, 5:121-6. 10.1093/ehjqcco/qcy055

24. Mohamed MO, Rashid M, Farooq S, et al.: Acute myocardial infarction in severe mental illness: prevalence, clinical outcomes, and process of care in U.S. hospitalizations. Can J Cardiol. 2019, 35:821-30. 10.1016/j.cjca.2019.04.021

25. Westman J, Eriksson SV, Gissler M, et al.: Increased cardiovascular mortality in people with schizophrenia: a 24-year national register study. Epidemiol Psychiatr Sci. 2018, 27:519-27. 10.1017/S2045796017000166

26. Protty MB, Lacey A, Smith D, Hannoodee S, Freeman P: Increased morbidity, mortality and length of inhospital stay for patients with acute coronary syndrome with pre-morbid psychiatric diagnoses. Int J Cardiol. 2017, 236:5-8. 10.1016/j.ijcard.2017.01.067 
27. Schulman-Marcus J, Goyal P, Swaminathan RV, et al.: Comparison of trends in incidence, revascularization, and in-hospital mortality in ST-elevation myocardial infarction in patients with versus without severe mental illness. Am J Cardiol. 2016, 117:1405-10. 10.1016/j.amjcard.2016.02.006

28. Bodén R, Molin E, Jernberg T, Kieler H, Lindahl B, Sundström J: Higher mortality after myocardial infarction in patients with severe mental illness: a nationwide cohort study. J Intern Med. 2015, 277:727-36. 10.1111/joim.12329

29. Wu SI, Chen SC, Juang JJ, et al.: Diagnostic procedures, revascularization, and inpatient mortality after acute myocardial infarction in patients with schizophrenia and bipolar disorder. Psychosom Med. 2013, 75:52-9. 10.1097/PSY.0b013e31827612a6

30. Kurdyak P, Vigod S, Calzavara A, Wodchis WP: High mortality and low access to care following incident acute myocardial infarction in individuals with schizophrenia. Schizophr Res. 2012, 142:52-7. 10.1016/j.schres.2012.09.003

31. Brown S, Inskip H, Barraclough B: Causes of the excess mortality of schizophrenia . Br J Psychiatry. 2000, 177:212-7. 10.1192/bjp.177.3.212

32. Gill SS, Rochon PA, Herrmann N, et al.: Atypical antipsychotic drugs and risk of ischaemic stroke: population based retrospective cohort study. BMJ. 2005, 330:445. 10.1136/bmj.38330.470486.8F

33. Wang PS, Schneeweiss S, Avorn J, Fischer MA, Mogun H, Solomon DH, Brookhart MA: Risk of death in elderly users of conventional vs. atypical antipsychotic medications. N Engl J Med. 2005, 353:2335-41. 10.1056/NEJMoa052827

34. Hallbäck I, Hägg S, Eriksson AC, Whiss PA: In vitro effects of serotonin and noradrenaline reuptake inhibitors on human platelet adhesion and coagulation. Pharmacol Rep. 2012, 64:979-83. 10.1016/S17341140(12)70894-0

35. Casey DE, Zorn SH: The pharmacology of weight gain with antipsychotics . J Clin Psychiatry. 2001, 62 Suppl 7:4-10.

36. Citrome L, Jaffe A, Levine J, Allingham B, Robinson J: Relationship between antipsychotic medication treatment and new cases of diabetes among psychiatric inpatients. Psychiatr Serv. 2004, 55:1006-13. 10.1176/appi.ps.55.9.1006

37. Serretti A, Mandelli L: Antidepressants and body weight: a comprehensive review and meta-analysis . J Clin Psychiatry. 2010, 71:1259-72. 10.4088/JCP.09r05346blu

38. Tiihonen J, Mittendorfer-Rutz E, Torniainen M, Alexanderson K, Tanskanen A: Mortality and cumulative exposure to antipsychotics, antidepressants, and benzodiazepines in patients with schizophrenia: an observational follow-up study. Am J Psychiatry. 2016, 173:600-6. 10.1176/appi.ajp.2015.15050618

39. Straus SM, Bleumink GS, Dieleman JP, et al.: Antipsychotics and the risk of sudden cardiac death . Arch Intern Med. 2004, 164:1293-7.10.1001/archinte.164.12.1293

40. Douglas IJ, Smeeth L: Exposure to antipsychotics and risk of stroke: self controlled case series study . BMJ. 2008, 337:a1227. 10.1136/bmj.a1227

41. Jiang HY, Chen HZ, Hu XJ, et al.: Use of selective serotonin reuptake inhibitors and risk of upper gastrointestinal bleeding: a systematic review and meta-analysis. Clin Gastroenterol Hepatol. 2015, 13:4250.e3. 10.1016/j.cgh.2014.06.021 